\title{
Long Term Outcomes from CT-guided Indirect Cervical Nerve Root Blocks and their relationship to the MRI findings-A prospective Study
}

\author{
Bensler, Susanne ; Sutter, Reto ; Pfirrmann, Christian W A ; Peterson, Cynthia K
}

\begin{abstract}
PURPOSE To investigate long-term pain reduction and 'improvement' in patients with indirect cervical nerve-root-blocks in comparison to MRI findings. MATERIAL AND METHODS One hundred and twelve patients with MRI confirmed cervical radiculopathy and an indirect cervical nerveroot-block were included. Two radiologists independently evaluated the MRI examinations. 12 different MRI abnormalities at the level and side of infiltration were compared to pain relief and 'improvement' at 1-month, 3-months and 1-year post injection. RESULTS The proportion of patients reporting clinically relevant 'improvement' was $36.7 \%$ at 1 -month, $53.9 \%$ at 3 -months and $68.1 \%$ at 1 -year. At 1 -month post injection, a statistically significantly lower percentage of patients eventually requiring surgery reported improvement and lower NRS change scores compared to those who did not undergo surgery $(\mathrm{p}=$ 0.001). Patients with extrusion of the disc were around 4-times more likely to have surgery. At 1-year post-injection the presence of nerve-root compromise was significantly linked to treatment outcome $(\mathrm{p}=$ 0.011). CONCLUSION Patients with nerve root compression were more likely to report improvement at 1 year. Patients with disc extrusions have less pain relief and are 4 times more likely to go to surgery than patients with disc protrusions. KEY POINTS • Good long term outcomes after indirect nerve root infiltrations with non-particulate steroids. - The presence of nerve root compression was a predictive finding of 'improvement'. - Significantly less patients subsequently having surgery had lower NRS scores 1-month post injection. - There is less pain relief in patients with disc extrusions. • There are less improvement in patients with modic type I changes.
\end{abstract}

DOI: https://doi.org/10.1007/s00330-015-3758-4

Posted at the Zurich Open Repository and Archive, University of Zurich

ZORA URL: https://doi.org/10.5167/uzh-120565

Journal Article

Published Version

Originally published at:

Bensler, Susanne; Sutter, Reto; Pfirrmann, Christian W A; Peterson, Cynthia K (2015). Long Term Outcomes from CT-guided Indirect Cervical Nerve Root Blocks and their relationship to the MRI findings-A prospective Study. European Radiology, 25(11):3405-3413.

DOI: https://doi.org/10.1007/s00330-015-3758-4 


\title{
Long Term Outcomes from CT-guided Indirect Cervical Nerve Root Blocks and their relationship to the MRI findings- A prospective Study
}

\author{
Susanne Bensler ${ }^{1,2} \cdot$ Reto Sutter $^{1,2}$ - Christian W. A. Pfirrmann ${ }^{1,2}$. \\ Cynthia K. Peterson ${ }^{1,2}$
}

Received: 20 November 2014 /Revised: 25 February 2015 /Accepted: 31 March 2015 / Published online: 23 April 2015

(C) European Society of Radiology 2015

\begin{abstract}
Purpose To investigate long-term pain reduction and 'improvement' in patients with indirect cervical nerve-rootblocks in comparison to MRI findings.

Material and Methods One hundred and twelve patients with MRI confirmed cervical radiculopathy and an indirect cervical nerve-root-block were included. Two radiologists independently evaluated the MRI examinations. 12 different MRI abnormalities at the level and side of infiltration were compared to pain relief and 'improvement' at 1-month, 3-months and 1-year post injection.

Results The proportion of patients reporting clinically relevant 'improvement' was $36.7 \%$ at 1 -month, $53.9 \%$ at 3months and $68.1 \%$ at 1-year. At 1-month post injection, a statistically significantly lower percentage of patients eventually requiring surgery reported improvement and lower NRS change scores compared to those who did not undergo surgery $(\mathrm{p}=0.001)$. Patients with extrusion of the disc were around 4-
\end{abstract}

Electronic supplementary material The online version of this article (doi:10.1007/s00330-015-3758-4) contains supplementary material, which is available to authorized users.

Susanne Bensler

susanne.bensler@balgrist.ch

Reto Sutter

reto.sutter@balgrist.ch

Christian W. A. Pfirrmann

christian.pfirrmann@balgrist.ch

Cynthia K. Peterson

cynthia.peterson@balgrist.ch

1 Department of Radiology, Orthopedic University Hospital Balgrist, Forchstrasse 340, 8008 Zurich, Switzerland

2 Faculty of Medicine, University of Zurich, Pestalozzistrasse 3, 8091 Zurich, Switzerland times more likely to have surgery. At 1-year post-injection the presence of nerve-root compromise was significantly linked to treatment outcome $(\mathrm{p}=0.011)$.

Conclusion Patients with nerve root compression were more likely to report improvement at 1 year. Patients with disc extrusions have less pain relief and are 4 times more likely to go to surgery than patients with disc protrusions.

Key Points

- Good long term outcomes after indirect nerve root infiltrations with non-particulate steroids.

- The presence of nerve root compression was a predictive finding of 'improvement'.

- Significantly less patients subsequently having surgery had lower NRS scores 1-month post injection.

- There is less pain relief in patients with disc extrusions.

- There are less improvement in patients with modic type I changes.

Keywords Long term outcome - Cervical nerve root block . CT guided $\cdot$ Indirect $\cdot$ MRI

\section{Introduction}

Cervical spine pain as a result of irritation of a nerve root by disc herniation or degenerative changes is a common problem[1]. Neurologic symptoms are the result of a cascade of degenerative changes including loss of disc height, disc protrusion posteriorly into the canal, facet and/ or uncovertebral degeneration and hypertrophy of the ligamentum flavum resulting in spinal canal stenosis and/ or foraminal stenosis [2]. Cervical nerve root blocks play an important role in conservative treatment of patients with cervical radicular pain [3]. Computed tomography (CT) is fast, safe and accurate in guiding spinal injections [4]. 
Complications after direct selective cervical nerve root blocks are very rare, but the few reported cases have extremely serious consequences. Hodler et al. [5] reported two severe cases with ischemic myelopathy after this intervention. Other cases of transient or permanent tetraplegia, brain infarctions leading to death, arterial dissection or cortical blindness after direct cervical nerve root blocks are reported [4, 6-17].

The reported cases of complications are most often associated with dissection or intra-arterial injection of crystalline steroids $[5,6]$.

Because of the risk for complications, our radiology department stopped performing direct cervical foraminal nerve root blocks in June 2008. The new procedure of indirect cervical nerve root blocks has been performed at our hospital since 2009. The indirect nerve root block procedure has a dorsal approach and the needle tip touches the outer border of the facet joint. That means the needle tip is far away from the vessels. This procedure is described as a safer alternative with nearly as good short term outcomes compared to the direct cervical foraminal nerve root blocks [18].

Magnetic resonance imaging of the cervical spine is always performed before the intervention, in order to identify a reason for the pain.

The purpose of our study was to compare MRI findings with immediate pain reduction and more importantly longterm 'improvement' in patients having the new procedure of indirect cervical nerve root blocks with the aim to find out if there is the possibility to predict the outcomes of indirect cervical nerve root blocks on the basis of the MRI findings.

\section{Materials and methods}

\section{Patients}

We included 112 consecutive patients with MRI examinations who underwent CT-guided indirect cervical nerve root blocks at our institution between November 2009 and February 2013. All patients had answered the 15 minutes pain relief questionnaire and a short, outcomes-based telephone questionnaire interview after the intervention. The MR images were reviewed by two radiologists.

Only patients who fulfilled the following criteria were included in the study: (a) patients investigated, diagnosed and referred by board certified physicians for indirect cervical nerve root blocks, (b) symptoms of nerve root compression from disc herniation, foraminal stenosis, or both (c) availability of cervical spine MR images which were acquired no longer than 3 months before the nerve root block, (d) requested cervical nerve root block at only one level and side of the cervical spine, (e) patients had to be able to rate pain relief before and 15 minutes after the nerve root block and respond to the questions on the postal questionnaire returned 1 month after the injection as well as the telephone interviews done at 3 months and 1 year post injection.

Exclusion criteria were: (a) previously performed surgery of the cervical spine, (b) repeated infiltrations within 1 year after the first included infiltration on the same side of the cervical spine (c) bilateral cervical nerve root blocks .

Informed consent was obtained before the intervention. The process of the intervention, the risks and benefit were discussed with the patients.

The study was approved by the institutional review boards. (EK 08/2009)

\section{MR Imaging}

The patients were examined with a 1.5-T (Avanto; Siemens Medical Solutions, Erlangen, Germany or Espree; Siemens Medical Solutions, Erlangen, Germany), or a 3-T (Verio; Siemens Medical Solutions, Erlangen, Germany) MR imaging unit at our institution. The patients were placed in prone position with the cervical spine in a spine coil. The complete MR imaging protocol is given as supplementary data (file 1).

Thirty four percent of the imaging examinations were brought by the patients performed at other institutions. We only included patients with MR examinations with a good quality comparable to our MR examinations and with similar sequences.

\section{MR Image analysis}

The MR images were analyzed independently by a fellowship-trained radiologist with 4 years experience in musculoskeletal radiology and a fellowship-trained radiologist with 1 year experience in musculoskeletal radiology and 1.5 years in neuroradiology. The MR images were reviewed on a picture archiving and communication system (PACS; Agfa Impax 6.4.0.6010). The radiologists were blinded to the clinical findings and the pain levels before and after the infiltration as well as to the 3 month and 1 year outcomes. They were informed of the level and side of infiltration. The complete analyzed pathologies are given as supplementary data (file 2).

\section{Cervical indirect nerve root block procedure and assessment of pain relief}

All indirect cervical nerve root injection procedures were performed as outpatient procedures by radiologists experienced in spinal interventions. The indirect cervical nerve root injections were performed by nine radiologists, all fellowship trained in musculoskeletal radiology and spinal interventions. Seven radiologists had an additional experience (1-15 years) in spinal interventions. All radiologists followed a 
standardized protocol to assure the consistency of the indirect cervical nerve root injection procedure.

The level and side of the intervention was clinically defined by the referring orthopaedic, neurologist, general practician or chiropractor.

The injections were controlled by CT (40-detector row CT, Philips Brilliance; Philips Medical Systems, Best, the Netherlands). The patients lay prone on the examination table with the head in a straight position. The head was fixed by a tape to prevent motion. CT acquisition was performed over $2-3$ cervical levels according to the previously obtained lateral scout view. The approach with the best access for the needle (23 gauge, $7 \mathrm{~cm}$ ) was chosen by the radiologist.

After skin disinfection and subcutaneous application of local anaesthetics the needle was introduced under fluoroscopic guidance at the lateral aspect of the chosen facet joint until the needle tip directly touched the bone of the facet joint (Fig. 1)(18). An injection of $0.5 \mathrm{ml}$ iopamidol (Iopamiro 200, $200 \mathrm{mg}$ of iodine per milliliter; Bracco, Milan, Italy) was performed to verify the correct position of the needle tip. Following the injection of contrast material, $4 \mathrm{mg}(1 \mathrm{ml})$ of the non-particulate corticosteroid preparation dexamethasone (Fortecortin Inject; Merck, Darmstadt, Germany) was slowly injected. This was followed by a slow injection of $1 \mathrm{ml}$ of $0.2 \%$ ropivacaine (Naropin; Astra-Zeneca, Södertälje, Sweden) (Figs. 2 and 3).

Pain levels were assessed using the numerical rating scale (NRS) where $0=$ no pain and $10=$ worst pain imaginable. Over-all improvement was evaluated with the 7 point Patient's Global Impression of Change (PGIC) scale where 1=much better and 7=much worse. Responses of 'much better' and 'better' counted as 'improvement' and this was the primary outcome measure. All other responses were considered as' not

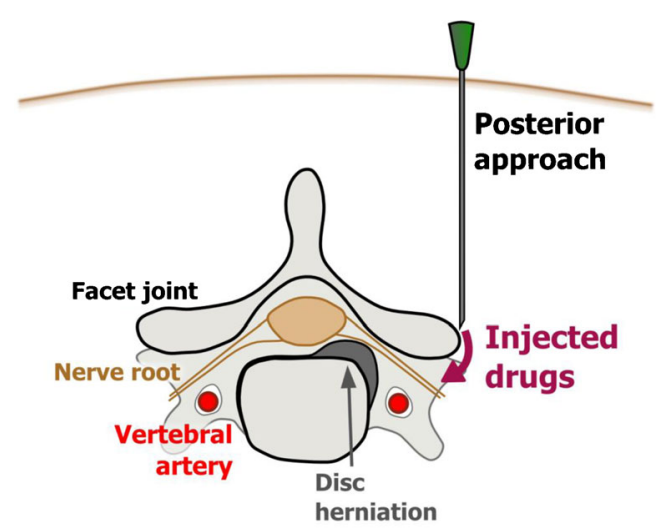

\section{Indirect nerve root block}

Fig. 1 Schema of indirect cervical nerve root block. Patient in prone position. The needle position is at the outer edge of the facet joint. The injected drugs flow around the articular process indirectly to the nerve root improved' for our analysis, including the response 'slightly better'.

Patients had to rate pain relief before and 15 minutes postinjection. Pain levels and over-all 'improvement' data were collected via a short postal questionnaire at 1 month postinjection and by a telephone interview at the 3 months and 1 year post-injection time points.

\section{Statistical analysis}

The proportion of patients reporting clinically relevant 'improvement' (primary outcome) was calculated for all data collection time points. Chi-squared test was used to compare individual imaging findings to 'Improvement' yes or no for all data collection time points. Logistic regression analysis was used to look for significant MRI predictors of improvement or surgery. The Mann-Whitney U and Kruskal-Wallis tests were used to compare the mean NRS and PGIC scores with imaging findings. The t-test was used to compare the NRS change scores with imaging findings and with surgery. Kappa test was used for the inter-rater reliability of MRI diagnosis.

All calculations were done with a statistical software package (SPSS Statistics Version 21, IBM, Chicago, IL).

\section{Results}

The mean patient age was 53.7 years $(\mathrm{SD}=13.11)$ and 63 (53\%) of the 112 patients were male. Thirty six patients had surgery at various points after their nerve root injection with 32 of the 36 surgical patients going to the operating theatre prior to the 3 month data collection time point. There was no significant age difference between patients with and without subsequent surgery $(\mathrm{p}=0.4)$. Surgical patients had a mean age of $51.47(\mathrm{SD}=13.77)$ years and non-surgical patients had a mean age of $53.97(\mathrm{SD}=12.80)$ years.

For the primary outcome, $36.7 \%$ of patients reported clinically relevant 'improvement' at 1 month, $53.9 \%$ at 3 months and $68.1 \%$ at 1 year (Table 1 ).

There were no significant differences in the baseline $(\mathrm{p}=$ $0.30)$ and 15 minute $(p=0.60)$ NRS scores between patients with and without subsequent surgery (Table 1). However, at 1 month post injection patients eventually requiring surgery had statistically significantly lower NRS change scores $(-.29$ $(\mathrm{SD}=2.7))$ compared to those who did have surgery $(2.85$ $(\mathrm{SD}=2.9)(\mathrm{p}=0.001)$.

For the primary outcome of 'improvement' at 1 month, there was a statistically significant association between 'improvement' and surgery, with $0 \%$ of patients eventually requiring surgery after the 1 month data collection point reporting clinically relevant improvement compared to $50.0 \%$ of patients not requiring surgery $(p=0.001)$ 


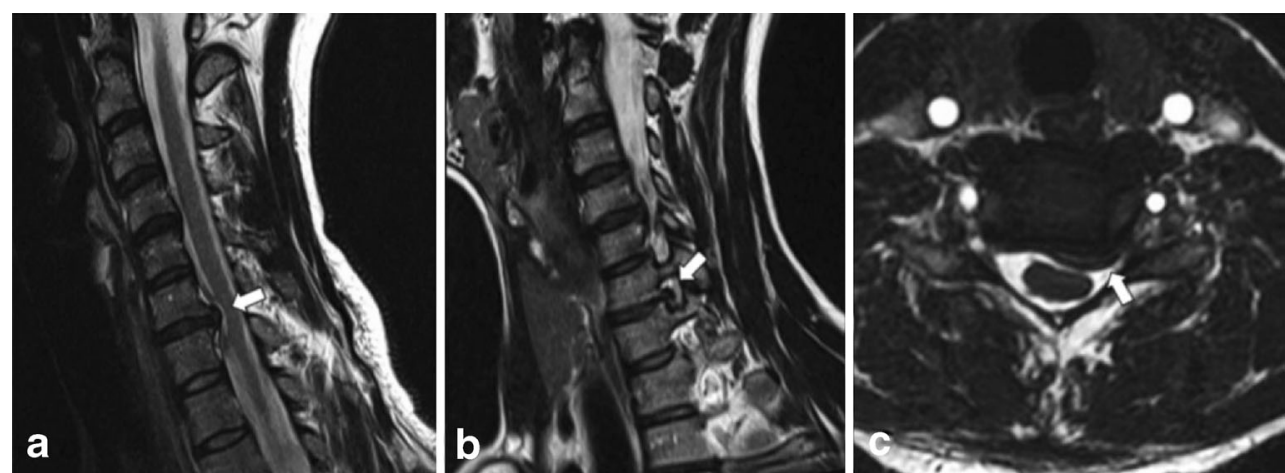

Fig. 2 Left sided C7 radiculopathy in 35-year-old woman. a, Sagittal T2 weighted turbo spin-echo MR image (4090/105, $2.5 \mathrm{~mm}$ slice thickness) shows a left sided disc extrusion at C6-C7 level. b, Left paramedian sagittal T2 weighted turbo spin-echo MR image (3000/115, $3 \mathrm{~mm}$ slice

(Table 1). The median PGIC scores of the surgical patients were also significantly higher than the non-surgical patients at 1 month $(\mathrm{p}=0.001)$.

The 3 month $(\mathrm{N}=76)$ and 1 year $(\mathrm{N}=72)$ results are only for patients not requiring surgery after their indirect cervical nerve root block.

Table 1 shows the proportion of patients reporting clinically relevant 'improvement' after 1 month, 3 months and 1 year (primary outcome). There were statistically significant reductions in the NRS scores at all follow-up data collection points.

Table 2 shows the inter-rater reliability Kappa values, Kappa classifications and percent agreement scores between the two raters for each of the MRI diagnoses. Agreement ranged from fair $(=.3)$ to substantial $(=.7)$.

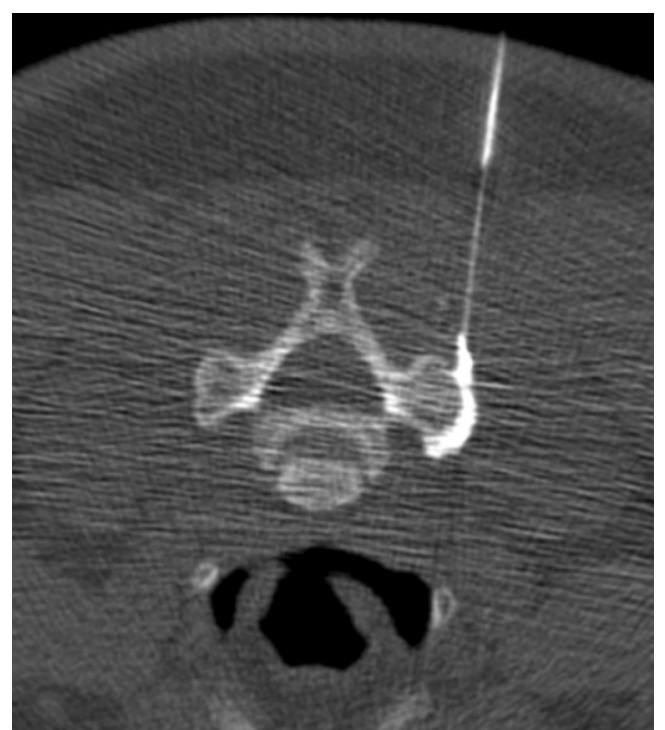

Fig. 3 Transverse CT fluoroscopy image of indirect cervical nerve root block in 61 year old man with right $\mathrm{C} 5$ radiculopathy. Dorsal approach at lateral border of the C4-C5 facet joint with a 25-gauge needle. Image shows the distribution of the contrast media around the articular process to the nerve root thickness) shows a moderate $\mathrm{C} 7$ nerve root compression at $\mathrm{C} 6-\mathrm{C} 7$ foramen level. c, Transverse T2 weighted 3D sequence $\left(9.02 / 4.51,70^{\circ}\right.$ flip angle, $2 \mathrm{~mm}$ slice thickness) shows the disc extrusion at foraminal entrance with the nerve root compromise

Table 3 shows the percentage of patients with the various MRI findings for each of the two evaluators.

None of the individual MRI abnormalities were significantly associated with 'improvement' at 1 or 3 months post injection for both raters using the Chisquared test. However, at 1 year post-injection the presence of nerve root compromise (yes/no) was significantly linked to treatment outcome $(p=0.011)$ for both raters with $67.6 \%$ of the patients having compression of the nerve root reporting clinically relevant 'improvement' compared to $33.3 \%$ of patients without nerve root compression. A similar tendency was noted at the 3 month data collection time point but this did not reach statistical significance $(p=0.06)$. However, the severity of nerve root compression was not significantly associated with 'improvement' $(\mathrm{p}=0.16)$.

Direct logistic regression analysis was done for each of the two raters individually using the 7 MRI findings that had moderate to substantial inter-rater reliability compared to 'improvement' yes or no for 1 month, 3 months and 1 year post injection (disc herniation classification, location of nerve root compression, severity of nerve root compression, origin of nerve root compression, grade of foraminal stenosis, origin of foraminal stenosis, Modic changes). However, no MRI finding was linked to 'improvement' for both raters at any of these time points. The presence of Modic change type I showed a tendency for less 'improvement' at 1 year for rater 1 with an odds ratio of $9.96(95 \%$ C.I. $=.8-$ 123.82).

The results of the direct logistic regression analysis comparing the impact of these same 7 MRI findings that had moderate to substantial inter-rater reliability with whether or not the patient subsequently had surgery showed that the model as a whole was able to distinguish between 20.4 and $28.7 \%$ of the variability in need for surgery, and correctly classified $74.0 \%$ of the cases. The sensitivity was 
Table 1 Outcomes at the various time points post injection

\begin{tabular}{|c|c|c|c|c|c|}
\hline Baseline & & 15 Minutes & $\begin{array}{l}1 \text { Month (Includes } 14 \\
\text { patients subsequently } \\
\text { going to surgery) }\end{array}$ & $\begin{array}{l}3 \text { Months }(\mathrm{N}=76) \\
\text { (Excludes surgical } \\
\text { patients) }\end{array}$ & $\begin{array}{l}1 \text { Year }(\mathrm{N}=72) \\
\text { (Excludes surgical } \\
\text { patients) }\end{array}$ \\
\hline $\begin{array}{l}\text { ALL PATIENTS NRS } \\
\text { Mean }(+\mathrm{SD})\end{array}$ & $6.69(2.21)$ & $4.37 *(2.55)$ & $4.18 *(3.09)$ & $3.34 *(2.98)$ & $2.35^{*}(2.86)$ \\
\hline \multirow[t]{2}{*}{ ALL PATIENTS PGIC } & & & $36.7 \%$ (41/112) Improved & $53.9 \%$ (41/76) Improved & $\begin{array}{l}68.1 \%(49 / 72) \\
\text { Improved }\end{array}$ \\
\hline & & & $13.2 \%(14 / 112)$ Worse & $7.9 \%(6 / 76)$ Worse & $5.1 \%(4 / 72)$ Worse \\
\hline $\begin{array}{l}\text { SURGICAL PATIENTS } \\
\text { ONLY NRS }\end{array}$ & $7.01(2.36)$ & $4.56^{*}(2.38)$ & $6.04(2.41)$ & & \\
\hline $\begin{array}{l}\text { NON-SURGICAL PATIENTS } \\
\text { ONLY NRS }\end{array}$ & $6.54(2.14)$ & $4.14 *(2.58)$ & $3.46 *(3.04)$ & & \\
\hline \multirow{2}{*}{$\begin{array}{l}\text { SURGICAL PATIENTS } \\
\text { ONLY PGIC }\end{array}$} & & & 0 \% Improved $(0 / 36)$ & & \\
\hline & & & $27.8 \%(10 / 36)$ Worse & & \\
\hline \multirow{2}{*}{$\begin{array}{l}\text { NON-SURGICAL } \\
\text { PATIENTS ONLY PGIC }\end{array}$} & & & $50.0 \%$ (38/76) Improved & & \\
\hline & & & $5.2 \%(4 / 76)$ Worse & & \\
\hline
\end{tabular}

$*=\mathrm{p}<0.001 . \mathrm{NRS}=$ Numerical rating scale for pain. PGIC $=$ Patient's Global Impression of Change

$43.3 \%$, the specificity was $87.9 \%$, the positive predictive value was $62 \%$ and the negative predictive value was $77 \%$. Only 1 independent variable, 'disc herniation classification' made a statistically significant contribution to the model with an odds ratio of 4.09 (95 \% C.I. $=1.1-15.26)$ for rater 1 and an odds ratio of 3.01 (95\% C.I=.7 - 10.7) for rater 2. Patients with extrusion of the disc were approximately 3 to 4 times more likely to go to surgery compared to patients with protrusion of the disc. Only $25.9 \%$ of patients with protrusion required surgery compared to $100 \%$ of patients with discal extrusion.

Rater 1 diagnosed disc protrusion in $74.8 \%$, extrusion in $19.3 \%$ and sequestration in only $.8 \%$ of patients. Rater 2 diagnosed protrusion in $79 \%$, extrusion in $16 \%$ and sequestration in $.8 \%$ of patients.

\section{Discussion}

The purpose of this study was to assess the long term outcomes of patients receiving the indirect cervical nerve root injection technique using a dorsal approach, and to determine if it is possible to make a prediction from specific MRI findings as to the likelihood of clinically relevant 'improvement' and pain reduction after indirect cervical nerve root blocks as well as to predict the likelihood of subsequent surgical treatment. With our study we present the first long term outcomes of indirect cervical nerve root blocks. We confirm the good short term outcomes similar to the study by Sutter et al. [18] and can even show further improvement of pain relief and 'patients global impression of change' with the long term results particularly in patients who did not require surgery.
Table 2 Inter-rater reliability of MRI Diagnosis. ( $\mathrm{SE}=$ Standard Error; $\mathrm{NR}=$ nerve root)

\begin{tabular}{lllll}
\hline Imaging Finding & $\begin{array}{l}\text { Kappa } \\
\text { (SE) }\end{array}$ & Kappa Classification & \% Agreement & Significance \\
\hline Disc Herniation Location & $.34(.07)$ & Fair & $59 \%$ & .0001 \\
$\begin{array}{l}\text { Disc Herniation } \\
\text { Classification }\end{array}$ & $.72(.08)$ & Substantial & $91 \%$ & .0001 \\
Nerve Root Compromise & $.39(.28)$ & Fair (but almost moderate) & $97 \%$ & .0001 \\
Location of Compromise & $.56(.07)$ & Moderate & $79 \%$ & .0001 \\
Severity of NR Compr & $.45(.09)$ & Moderate & $80 \%$ & .0001 \\
Origin of NR Compr & $.49(.08)$ & Moderate & $75 \%$ & .0001 \\
Grade Foraminal Stenosis & $.43(.06)$ & Moderate & $59 \%$ & .0001 \\
Origin of Foraminal Stenosis & $.50(.10)$ & Moderate & $82 \%$ & .0001 \\
Cervical Facet Joints & $.36(.07)$ & Fair & $64 \%$ & .0001 \\
Cervical Canal Stenosis & $.30(.06)$ & Fair & $54 \%$ & .0001 \\
Modic Changes & $.62(.07)$ & Substantial & $82 \%$ & .0001 \\
Disc Degeneration Severity & $.29(.07)$ & Fair & $62 \%$ & .0001 \\
\hline
\end{tabular}


Table 3 Proportion of patients with the various MRI findings by Rater

\begin{tabular}{|c|c|c|}
\hline Imaging Finding & Rater 1 & Rater 2 \\
\hline \multirow[t]{4}{*}{ Disc Herniation Location } & Central $1.8 \%$ & Central $0.9 \%$ \\
\hline & Paracentral $17.8 \%$ & Paracentral $27.1 \%$ \\
\hline & Foraminal $15.0 \%$ & Foraminal $29.0 \%$ \\
\hline & General $65.4 \%$ & General $43.0 \%$ \\
\hline \multirow[t]{3}{*}{ Disc Herniation Classification } & Protrusion $82.2 \%$ & Protrusion $78.5 \%$ \\
\hline & Extrusion $16.8 \%$ & Extrusion $20.6 \%$ \\
\hline & Sequestration $0.9 \%$ & Sequestration $0.9 \%$ \\
\hline \multirow[t]{2}{*}{ Nerve Root Compromise } & No $2.8 \%$ & No $1.9 \%$ \\
\hline & Yes $97.2 \%$ & Yes $98.1 \%$ \\
\hline \multirow[t]{3}{*}{ Location of Compromise } & Intraspinal $1.9 \%$ & Intraspinal $4.7 \%$ \\
\hline & Foraminal entrance $46.2 \%$ & Foraminal entrance $32.7 \%$ \\
\hline & Foraminal $51.9 \%$ & Foraminal $62.6 \%$ \\
\hline \multirow[t]{3}{*}{ Severity of NR Compromise } & Contact $3.8 \%$ & Contact $7.5 \%$ \\
\hline & NR deviation $20.7 \%$ & NR deviation $14.0 \%$ \\
\hline & NR compression $75.5 \%$ & NR compression $78.5 \%$ \\
\hline \multirow[t]{2}{*}{ Origin of NR Compromise } & Discogenic $38.1 \%$ & Discogenic $50.0 \%$ \\
\hline & Mixed $61.9 \%$ & Mixed $50.0 \%$ \\
\hline \multirow[t]{4}{*}{ Grade Foraminal Stenosis } & $010.1 \%$ & $011.9 \%$ \\
\hline & $120.2 \%$ & $123.9 \%$ \\
\hline & $238.5 \%$ & $215.6 \%$ \\
\hline & $331.2 \%$ & $348.6 \%$ \\
\hline \multirow[t]{3}{*}{ Origin of Foraminal Stenosis } & Discogenic $12.2 \%$ & Discogenic $26.0 \%$ \\
\hline & Mixed $86.8 \%$ & Mixed $72.9 \%$ \\
\hline & Osseous $1.0 \%$ & Osseous $1.1 \%$ \\
\hline \multirow[t]{3}{*}{ Cervical Facet Joint Degeneration } & $035.8 \%$ & $062.4 \%$ \\
\hline & $158.7 \%$ & $135.8 \%$ \\
\hline & $25.5 \%$ & $21.8 \%$ \\
\hline \multirow[t]{4}{*}{ Cervical Canal Stenosis } & $011.9 \%$ & $040.4 \%$ \\
\hline & $170.6 \%$ & $139.4 \%$ \\
\hline & $217.5 \%$ & $219.3 \%$ \\
\hline & $30.0 \%$ & 30.9 \\
\hline \multirow[t]{4}{*}{ Modic Changes } & $068.8 \%$ & $069.7 \%$ \\
\hline & $116.5 \%$ & $113.8 \%$ \\
\hline & $211.0 \%$ & $214.7 \%$ \\
\hline & $33.7 \%$ & $31.8 \%$ \\
\hline \multirow[t]{5}{*}{ Disc Degeneration Severity } & $20.0 \%$ & $24.6 \%$ \\
\hline & $322.9 \%$ & $311.0 \%$ \\
\hline & $466.1 \%$ & $461.4 \%$ \\
\hline & $511.0 \%$ & $519.3 \%$ \\
\hline & $60.0 \%$ & $63.7 \%$ \\
\hline
\end{tabular}

$\mathrm{NR}=$ nerve root.

Although most MRI abnormalities were not associated with 'improvement' at the various post-injection time points, the specific finding of disc extrusion was predictive for the likelihood of surgical treatment. Patients with this MRI finding were four times more likely to require surgery compared to patients with disc protrusion. The only MRI abnormality linked to 'improvement' after cervical indirect nerve root injections for both raters was the finding of nerve root compromise. Patients with nerve root compromise were significantly more likely to report 'improvement' at the 1 year data collection time point compared to patients without nerve root compromise with a similar tendency at the 3 month data collection time point. Interestingly, the severity of nerve root compression was not associated with improvement however. 
One rater also found a tendency for Modic type I changes to be predictive of a worse outcome at 1 year post-injection. Our results, with the exception of the relationship of nerve root compromise to improvement and the tendency for less improvement in patients with Modic type I changes, are similar to the findings by Klessinger et al. [19, 20]. They found no direct link between MR findings and pain reduction but they only looked at short-term outcomes 1 month post-injection.

In cervical radicular pain caused by nerve root compression, the first choice in therapy is often noninvasive, including medication, physiotherapy, manual therapy, acupuncture and warmth. If the noninvasive treatments are not effective, the next therapeutic option before surgery can be the cervical nerve root block with local anaesthesia and cortisone. In this technique the drugs are placed around the affected nerve root with the goal to control the pain at the location of the nerve root compression.

Starting in 2009 our specialized orthopaedic/rheumatology university hospital has performed cervical nerve root blocks using a dorsal indirect approach, because it is considered to be a safer method with less potential for complications compared to the direct cervical nerve root blocks. This is due to the larger distance to the vessels including the vertebral artery with less potential for complications such as arterial dissection or injection of drugs in brain-supplying arteries. Reported complications from the traditionally used direct cervical nerve root blocks include spinal cord and brain infarction which occur by penetrating the vertebral artery, the nerve root artery [5, 8-18] and small arteries in the intervertebral foramen [7]. Hodler et al. reported two detrimental complications after technically correct direct cervical nerve root with cervical myelopathy and complete tetraplegia as well as persisting severe deficiencies after rehabilitation [5].

The method of indirect cervical nerve root blocks was described and short-term outcomes compared to the method of direct cervical nerve root blocks by Sutter et al. [18]. The indirect cervical nerve root block procedure with a extraforaminal dorsal approach to the nerve root is somewhat similar to the method described by Wolter et al. with a higher degree of safety and a comparable outcome than found in the formerly used direct techniques [18-20].

Short term (15 minutes) pain relief for direct cervical nerve root blocks was reported by Strobel et al. in their study [21]. The 15 minute post-intervention visual analogue scale for pain (VAS) grade shows the short term outcome i.e. the diagnostic effect of the ropivacaine anaesthetic. The effects of local anaesthetics last approximately 1-15 hours [22-24]. Sutter et al. compared the short term outcomes of pain reduction (15 minutes) of the direct and indirect approaches for cervical nerve root blocks. There was no statistically significant difference in pain reduction comparing the direct and indirect approaches [18].
The additional application of steroid theoretically causes a prolonged effect. Bush et al. reported a satisfactory long term (4-112 months) recovery after serial periradicular and epidural injections in the cervical spine in their study with 68 patients [25].

Approximately a third (35.4\%) of 48 patients had a benefit from fluoroscopic guided direct cervical intraforaminal injection of $0.5 \mathrm{~mL}$ triamcinolone $(2.5 \mathrm{mg})$ and bupivacaine in the evaluation one month after the injection in the survey of Klessinger et al. [19].

Statistically significant pain reduction at 15 minutes, 1 month and 3 months after direct CT-guided cervical nerve root injections were reported by Desai et al. [26].

Kolstad et al. reported a significant improvement of pain in the 6 weeks and 4 months evaluation and reduction in operative requirement after repeated fluoroscopic direct guided intraforaminal injections [27].

Our results relating the MRI findings to pain relief confirm the results of Klessinger et al. [20] in that the MRI findings evaluated in this study are not predictive of the outcome of a cervical nerve root block. Our results, obtained at much longer follow-up periods, contradict the results of Strobel et al. [21] in which they found the greatest pain relief at 15 minutes post injection for patients with foraminal disc herniation, foraminal nerve root compromise and no spinal canal stenosis. However, only immediate post-injection pain levels were recorded in that study. Thus it is unknown if they would have found similar results at later, more clinically relevant follow-up time points.

The main limitation to our study is the fact that this is a cohort outcome study and not a randomized controlled clinical trial with a control group. Thus the results disclosed cannot definitively be linked to the indirect nerve root injection. At least for acute patients much of the outcome may be due to natural history $[8,27]$. To reduce this limitation factor we retrospectively reviewed a representative group of the patient population from our highly specialized orthopaedic hospital, to show that the majority of patients belong to the category subacute/ chronic pain. Thus these patients should have passed the time period for improvement due to natural history. A further limitation is that the 1 month data collection was by postal questionnaire and the 3 months and 1 year data collection was by telephone interview. It is known from previous studies that patients with worse outcomes are more likely to return postal questionnaires [28, 29]. This may be one reason for the worse outcomes at 1 month. At a telephone interview the patients may be positively surprised at receiving a call and the interest of the hospital in their physical condition such that they may tend to impress the interviewer with an outcome better than it really was [28].

A larger factor in the better outcomes at 3 months and 1 year is more likely to be that those patients who required surgery were no longer considered at those time points. 
Further because this is a prospective study and not a randomized, controlled, clinical trial, the outcomes from the indirect cervical nerve root blocks cannot be definitively attributed to the treatment.

\section{Conclusion}

This is the first study investigating the short and long term effects of indirect cervical nerve root blocks. A statistically significant pain reduction at all data collection points was noted. The MRI diagnosis of disc extrusion was the only MRI finding that was predictive of the likelihood of requiring surgical intervention after the indirect nerve root block. Patients with nerve root compression on MRI were significantly more likely to report improvement at 1 year post-injection with a strong tendency also at 3 months. There was also a tendency for patients with Modic type I changes to be less likely report clinically relevant 'improvement' at 1 year.

Acknowledgments The scientific guarantor of this publication is Susanne Bensler. The authors of this manuscript declare no relationships with any companies, whose products or services may be related to the subject matter of the article. The authors state that this work has not received any funding. No complex statistical methods were necessary for this paper. Institutional Review Board approval was obtained. Written informed consent was obtained from all subjects (patients) in this study. Methodology: prospective and retrospective, diagnostic or prognostic study, performed at one institution.

\section{References}

1. Martin BI, Deyo RA, Mirza SK et al (2008) Expenditures and health status among adults with back and neck problems. JAMA 299:656-664

2. Rao R (2002) Neck pain, cervical radiculopathy, and cervical myelopathy: pathophysiology, natural history, and clinical evaluation. J Bone Joint Surg Am 84-A:1872-1881

3. Dreyfuss P, Baker R, Bogduk N (2006) Comparative effectiveness of cervical transforaminal injections with particulate and nonparticulate corticosteroid preparations for cervical radicular pain. Pain Med 7:237-242

4. Wagner AL (2005) CT fluoroscopic-guided cervical nerve root blocks. AJNR Am J Neuroradiol 26:43-44

5. Hodler J, Boos N, Schubert M (2013) Must we discontinue selective cervical nerve root blocks? Report of two cases and review of the literature. Eur Spine J 22(Suppl 3):S466-S470

6. Scanlon GC, Moeller-Bertram T, Romanowsky SM, Wallace MS (2007) Cervical transforaminal epidural steroid injections: more dangerous than we think? Spine 32:1249-1256, Phila Pa 1976

7. Huntoon MA (2005) Anatomy of the cervical intervertebral foramina: vulnerable arteries and ischemic neurologic injuries after transforaminal epidural injections. Pain 117:104-111

8. Baker R, Dreyfuss P, Mercer S, Bogduk N (2003) Cervical transforaminal injection of corticosteroids into a radicular artery: a possible mechanism for spinal cord injury. Pain 103:211-215
9. Brouwers PJ, Kottink EJ, Simon MA, Prevo RL (2001) A cervical anterior spinal artery syndrome after diagnostic blockade of the right C6-nerve root. Pain 91:397-399

10. Rosenkranz M, Grzyska U, Niesen W et al (2004) Anterior spinal artery syndrome following periradicular cervical nerve root therapy. J Neurol 251:229-231

11. Karasek M, Bogduk N (2004) Temporary neurologic deficit after cervical transforaminal injection of local anesthetic. Pain Med 5 : 202-205

12. Tiso RL, Cutler T, Catania JA, Whalen K (2004) Adverse central nervous system sequelae after selective transforaminal block: the role of corticosteroids. Spine J 4:468-474

13. Wallace MA, Fukui MB, Williams RL, Ku A, Baghai P (2007) Complications of cervical selective nerve root blocks performed with fluoroscopic guidance. AJR Am J Roentgenol 188:1218-1221

14. Okubadejo GO, Talcott MR, Schmidt RE et al (2008) Perils of intravascular methylprednisolone injection into the vertebral artery. An animal study. J Bone Joint Surg Am 90:1932-1938

15. Suresh S, Berman J, Connell DA (2007) Cerebellar and brainstem infarction as a complication of CT-guided transforaminal cervical nerve root block. Skeletal Radiol 36:449-452

16. Rozin L, Rozin R, Koehler SA et al (2003) Death during transforaminal epidural steroid nerve root block (C7) due to perforation of the left vertebral artery. Am J Forensic Med Pathol 24: 351-355

17. Furman MB, Giovanniello MT, O'Brien EM (2003) Incidence of intravascular penetration in transforaminal cervical epidural steroid injections. Spine 28:21-25, Phila Pa 1976

18. Sutter R, Pfirrmann CW, Zanetti M, Hodler J, Peterson CK (2011) CT-guided cervical nerve root injections: comparing the immediate post-injection anesthetic-related effects of the transforaminal injection with a new indirect technique. Skeletal Radiol 40:1603-1608

19. Wolter T, Knoeller S, Berlis A, Hader C (2010) CT-guided cervical selective nerve root block with a dorsal approach. AJNR Am J Neuroradiol 31:1831-1836

20. Klessinger S, Freund W, Karpel-Massler G, Halatsch ME (2014) Response to Transforaminal Injection of Steroids and Correlation to MRI Findings in Patients with Cervical Radicular Pain or Radiculopathy due to Disc Herniation or Spondylosis. Pain Med 15:929-937

21. Strobel K, Pfirrmann CW, Schmid M, Hodler J, Boos N, Zanetti M (2004) Cervical nerve root blocks: indications and role of MR imaging. Radiology 233:87-92

22. Butterworth JF, Strichartz GR (1990) Molecular mechanisms of local anesthesia: a review. Anesthesiology 72:711-734

23. Sato C, Sakai A, Ikeda Y, Suzuki H, Sakamoto A (2008) The prolonged analgesic effect of epidural ropivacaine in a rat model of neuropathic pain. Anesth Analg 106:313-320, table of contents

24. Toda S, Sakai A, Ikeda Y, Sakamoto A, Suzuki H (2011) A local anesthetic, ropivacaine, suppresses activated microglia via a nerve growth factor-dependent mechanism and astrocytes via a nerve growth factor-independent mechanism in neuropathic pain. Mol Pain 7:2

25. Bush K, Hillier S (1996) Outcome of cervical radiculopathy treated with periradicular/epidural corticosteroid injections: a prospective study with independent clinical review. Eur Spine J 5:319-325

26. Desai A, Saha S, Sharma N, Huckerby L, Houghton R (2014) The short- and medium-term effectiveness of CT-guided selective cervical nerve root injection for pain and disability. Skeletal Radiol 43: 973-978

27. Kolstad F, Leivseth G, Nygaard OP (2005) Transforaminal steroid injections in the treatment of cervical radiculopathy. A prospective outcome study. Acta Neurochir (Wien) 147:1065-1070, discussion 1070

28. Kremer S, Pfirrmann CW, Hodler J, Peterson CK (2012) Imagingguided lumbar facet injections: is there a difference in outcomes 
between low back pain patients who remember to return a postal questionnaire and those who do not? Insights Imaging 3:411-418

29. Lechmann M, Peterson CK, Pfirrmann CW, Hodler J (2013)

Lumbar nerve root injections: a prospective cohort outcomes study comparing age- and gender-matched patients who returned an outcomes-based postal questionnaire with patients who did not return the postal questionnaire. Skeletal Radiol 42: 1429-1435 